\title{
Research on Slider Stiffness for Straight Side Two- point High Speed Precision Press Based on Solidworks Simulation
}

\author{
Xinjian $\mathrm{Lu}^{1,2,3}$ \\ ${ }^{1}$ School of Mechanical Engineering,Nanjing Institute of Technology,Nanjing 211167,China \\ ${ }^{2}$ Research Department of Intelligent Manufacturing Equipment,Nanjing Institute of Technology,Nanjing 211167,China \\ ${ }^{3}$ Yangzhou SHUANGYING Metal Forming Machine Co.,Ltd. Yangzhou 225000,China
}

\begin{abstract}
Slider is an important power output component for high-speed precision presses, which requiring a higher stiffness (less deformation). The mold and stamping part's size were generally not considered for the traditional analysis method. In this paper, the length and thickness of the equivalent upper die and the size of the stamping parts were fully considered for the finite element analysis of the slider parts for a $3000 \mathrm{kN}$ straight side two-point high-speed precision press and the stiffness was much higher than the traditional one. Thestiffnesseffects of equivalent upper die thickness, feed width, equivalent upper die lengthand eccentric loadwere studied. The results show that: the effect of equivalent upper die thickness on the stiffness was greater than that of the feed width; the equivalent upper die length's shorten will result in a decrease of the stiffness of the slider; biasing the mold will improve the stiffness of the slider when using a small mold.
\end{abstract}

Keywords—slider stiffness; high-speed precision press; die size; partial load

\section{INTRODUCTION}

With the characteristics of automatic, precise and high efficiency High-speed precision press is widely used in modern industrial production and it is very suitable forstandardized, serialized and batch functional stamping parts(1).Compared with ordinary presses, high-speed precision presses require higher stiffness. Slideris an important power output components for the high-speed precision press and its stiffness directly affects the accuracy of stamping parts and die life. When calculating the deformation caused by the bending normal stress and the bending shear stress the slider is regarded as a stout beam, which is very different from the actual situation. And the allowable deformation is taken as 1/6000 1/8000 slider length(2).The existing researches(3-6) mostly focus on the stress and deformation of the slider under static load and the structure optimization based on the purpose of weight loss. The impact of the mold (geometric size, partial load, etc.) is not considered in the analysis. The $3000 \mathrm{kN}$ straight side two-point high-speed precision press (for the stater and rotors' stamping) was researched considering the stamping parts and mold on the slider stiffness in this article. Research results for reference only.

\section{SLIDER STRUCTURE}

The slider structure of the $3000 \mathrm{kN}$ straight side two-point high-speed precision press is shown in Figure I. The slider body was cast from HT300. For precision repair after long-time using the transition plate (usually made of hard aluminum alloy or Q235A steel) was usually installed in the bottom of slider body by bolts. This additional transition plate helps to increase the rigidity of the slider and needs to be taken into account in analysis. Upper mold was fixed below the transition plate by the T-bolts and the connection stiffness was not considered in the later analysis.

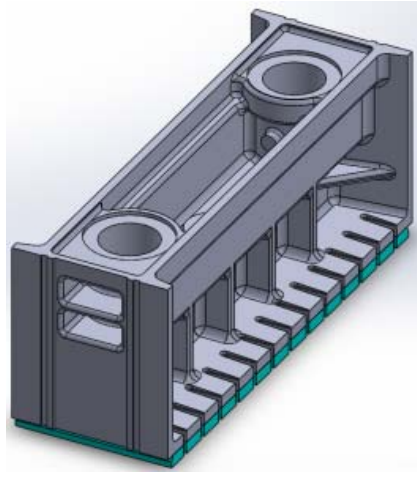

FIGURE I. SLIDER STRUCTURE

\section{DIE SIZE AND FEED WIDTH}

The maximum allowable die weight wasdesigned to $2000 \mathrm{~kg}$ for the $3000 \mathrm{kN}$ press. The size of the bottom surface of the slider was designed to 2300 (Left and right) x800(before and after) $\mathrm{mm}$ and the height of the die is $470 \sim 520 \mathrm{~mm}$. According to the provisions of the detection range in GB / T 29548-2013 high speed precision straight side press-Testing of the accuracy, the size of the mold is assumed to be $2100 \times 640 \mathrm{~mm}$ or less. The upper die thickness is generally less than half the die height and the thickness is about $190.8 \mathrm{~mm}$ (Die steel density in accordance with $7800 \mathrm{~kg} / \mathrm{m} 3$ calculation).

Double or triple progressive die was generally installed in the $3000 \mathrm{kN}$ press and material width is $450 \mathrm{~mm}, 400 \mathrm{~mm}$, $350 \mathrm{~mm}$ and $300 \mathrm{~mm}$ and other specifications. Therefore, the width of force zone can be divided according to the above material width inbottom of the equivalent upper mold. 


\section{FINITE ELEMENT ANALYSIS}

The slider components to be analyzed is composed of slider body, transition plate and equivalent upper die and the materials and properties are shown in Table I. The contact parameters in the assembly are set according to the system defaults.

TABLE I. MATERIAL PROPERTIES FOR SLIDER COMPONENTS

\begin{tabular}{|c|c|c|c|c|c|}
\hline & material & $\begin{array}{c}\text { Elastic } \\
\text { Modulus } \\
/ \mathbf{G P a}\end{array}$ & $\begin{array}{c}\text { Poisso } \\
\mathbf{n} \text { 's } \\
\text { ratio }\end{array}$ & $\begin{array}{c}\text { Yield } \\
\text { stress } \\
/ \mathbf{M P a}\end{array}$ & $\begin{array}{c}\text { Limit } \\
\text { stress } \\
/ \mathbf{M P a}\end{array}$ \\
\hline Slider body & $\mathrm{HT} 300$ & 143 & 0.27 & - & 300 \\
\hline $\begin{array}{c}\text { transition } \\
\text { plate }\end{array}$ & $\mathrm{Q} 235 \mathrm{~A}$ & 210 & 0.33 & 235 & 390 \\
\hline $\begin{array}{c}\text { equivalent } \\
\text { upper die }\end{array}$ & $20 \mathrm{Cr}$ & 210 & 0.3 & 540 & 640 \\
\hline
\end{tabular}

1/4 slider part was taken for analysis due to the symmetry of the structure and a symmetrical constraint was Applied on the symmetry section(shown in Figure II).A uniform load of $750 \mathrm{kN}$ is applied to the divided area(material width of $400 \mathrm{~mm}$ ) of the bottom of equivalentuppermold (shown in Figure II). And a fixing constraint was imposed on the lower guide sleeve's mounting surface in the slider body(shown in Figure II).The slider body has a very high guide stiffness due to eight guide rails used. Therefore, the guide parts of the slider body were not limited.

The system default parameters were used in grid types (solid grid, grid size $27.47 \mathrm{~mm}$, grid error $1.37 \mathrm{~mm}$ ). Meshed model was shown in Figure II and 138393 nodes and 91754 cells were gotten.

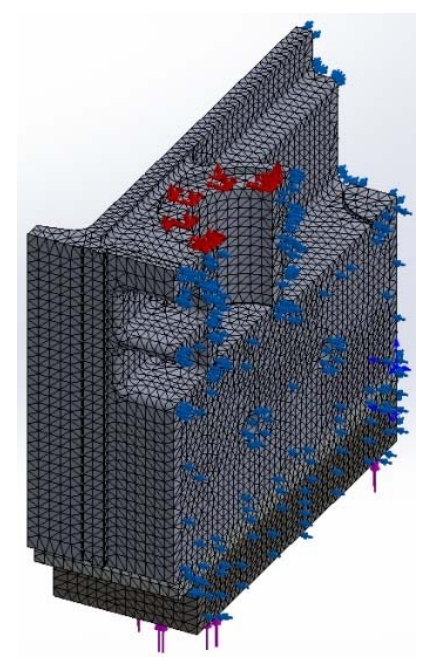

FIGURE II. MESHED SLIDER PARTS

\section{CAlCUlation Results}

As the slider body is made of brittle material(HT300), the tensile stress (P1) can be more appropriate to assess the structure's safety (7) and calculation results was shown in Figure III. The maximum stress of 29.6MPa appeared in the fillet and most of the rest of the stress were within $15 \mathrm{MPa}$. The calculated safety factor is 5.12, which is greater than the minimum allowable safety factor of 1.6 to 2.5 for brittle materials (8).

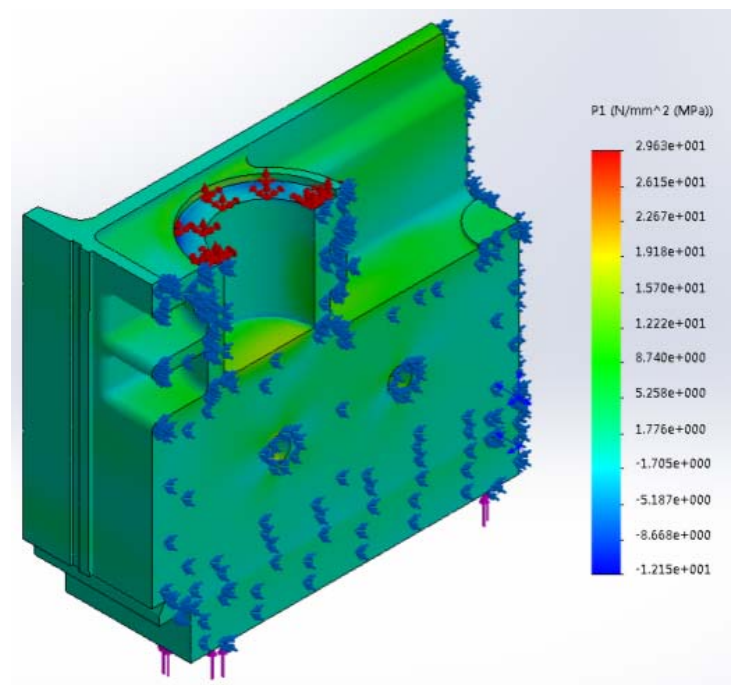

FIGURE III. STRESS DIAGRAM (TENSILE STRESS)

The Y-direction displacement diagram of the slider part was shown in Figure IV. The maximum displacement of $0.2742 \mathrm{~mm}$ appeared in the middle of the slider. For the slider, the displacement of the middle was $0.2690 \mathrm{~mm}$ and the outer was $0.1018 \mathrm{~mm}$. The deformation of the slider can be calculated as $0.1672 \mathrm{~mm}$ (the slider's stiffness is about 1/14055). The slider body length is $2350 \mathrm{~mm}$. Therefore, the allowable deformation is $0.294 \sim 0.392 \mathrm{~mm}$.

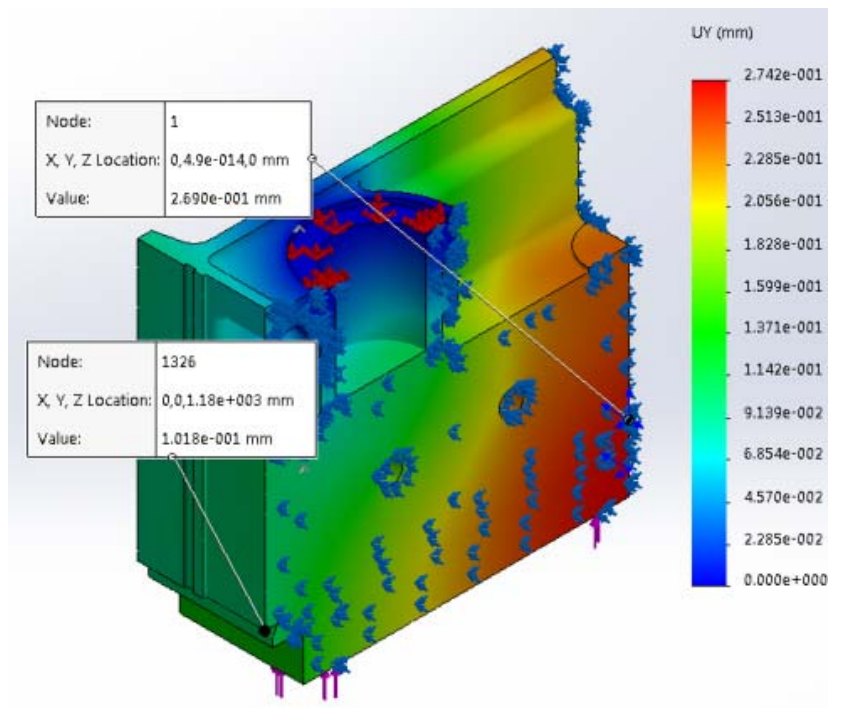

FIGURE IV. DISPLACEMENT DIAGRAM

\section{DISCUSS}

\section{A. Compare with Other Analysis Methods}

Loading method reference(2) provided was shown in Figure $\mathrm{V}$, where $\mathrm{L}$ is the left-right length of the slider and $l$ is the distance between the two plunges' center. And the fixed constraint was imposed on the two plunges. The uniform nominal force Pg is applied at $l(l=1600 \mathrm{~mm}$ and $\mathrm{Pg}=3000 \mathrm{kN}$ in this analysis). 


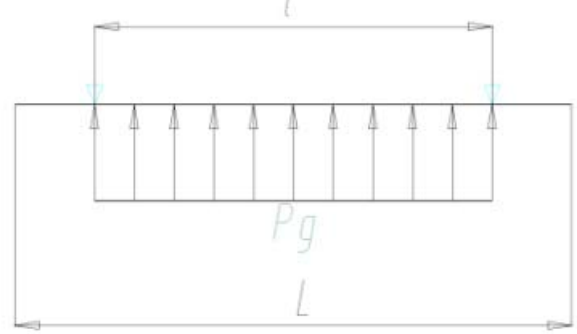

FIGURE V. SLIDER LOADING METHOD

1/4 slider parts taken to analysis according to the above loading method. Figure VI is the tensile stress diagram, the maximum stress reaches $88.9 \mathrm{MPa}$ and most of the stress at $45 \mathrm{MPa}$. The calculation results were larger.

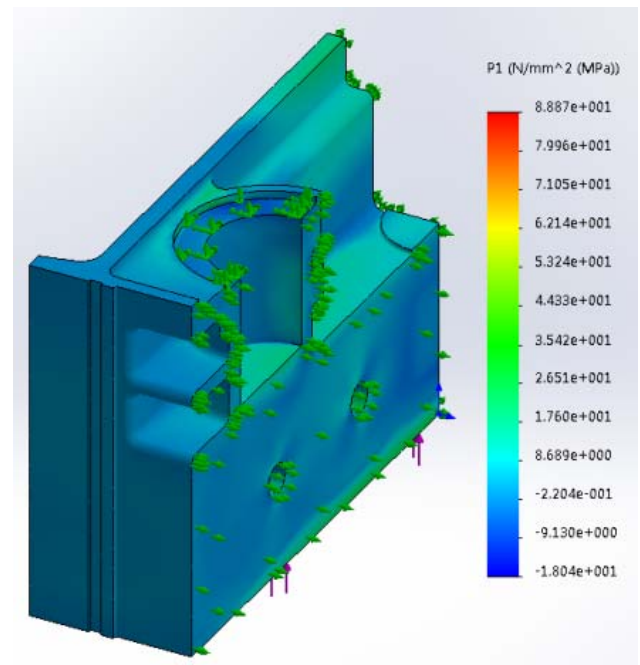

FIGURE VI. TENSILE STRESS DIAGRAM

Figure VII is the displacement diagram and the maximum displacement of $1.4 \mathrm{~mm}$ appeared in outside of the slider parts' central area. The displacement of the slider's central area is $0.430 \mathrm{~mm}$, and the outside displacement of the central area (left and right direction) is $0.010 \mathrm{~mm}$. Therefore, the deformation amount of the slider is $0.420 \mathrm{~mm}$, which is lower than the maximum deformation required.

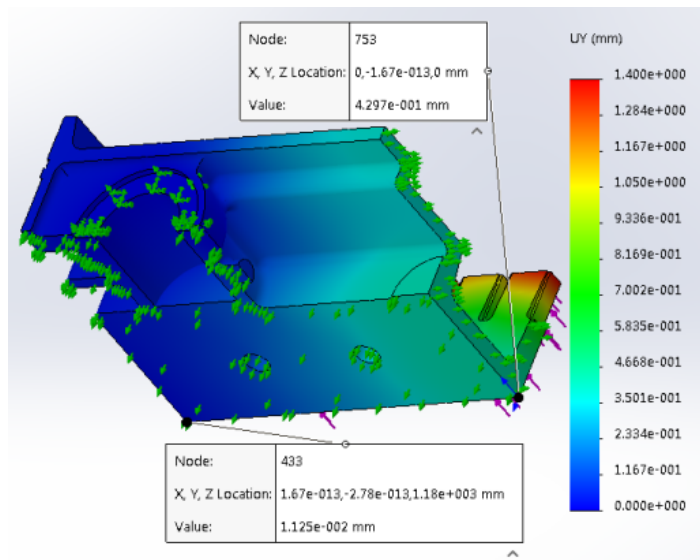

FIGURE VII. SLIDER PARTS’ DISPLACEMENT DIAGRAM

\section{B. Feeding Width and Mold Thickness}

Finite element analysis refereeing to the above constraints and loading method were performed by varying the equivalent upper die thickness (i.e, changing the upper die weight) and the feed width with the same die length and width. Equivalent upper die thickness were taken $170 \mathrm{~mm}, 150 \mathrm{~mm}, 130 \mathrm{~mm}$, $110 \mathrm{~mm}$ and $90 \mathrm{~mm}$. And the feed width were taken $450 \mathrm{~mm}$, $400 \mathrm{~mm}, 350 \mathrm{~mm}, 300 \mathrm{~mm}$ and $250 \mathrm{~mm}$. Table II was the slider deformation data. It can be seen from the following data that the effect of the equivalent upper die thickness on the slider stiffness is greater than the feed width.

TABLE II. SLIDER DEFORMATION WITH DIFFERENT FEED WIDTH AND THICKNESS OF THE EQUIVALENT UPPER DIE/ MM

\begin{tabular}{|c|c|c|c|c|c|}
\hline \multirow{2}{*}{$\begin{array}{c}\text { thickness } \\
\text { of the } \\
\text { equivalent } \\
\text { upper } \\
\text { die/mm }\end{array}$} & 250 & 300 & 350 & 400 & 450 \\
\cline { 2 - 6 } & & & & & \\
\hline 90 & 0.1826 & 0.1824 & 0.1823 & 0.1822 & 0.1821 \\
\hline 110 & 0.1787 & 0.1785 & 0.1784 & 0.1783 & 0.1783 \\
\hline 130 & 0.1747 & 0.1746 & 0.1746 & 0.1745 & 0.1745 \\
\hline 150 & 0.1710 & 0.1710 & 0.1709 & 0.1708 & 0.1708 \\
\hline 170 & 0.1673 & 0.1673 & 0.1672 & 0.1672 & 0.1672 \\
\hline
\end{tabular}

\section{Die Length}

Some small size mold (smaller punch force) also can installed on this $3000 \mathrm{kN}$ straight side two-point high-speed precision press. As the $2000 \mathrm{kN}$ and $1250 \mathrm{kN}$ straight side twopoint high-speed precision press's standard bolster length are generally $1700 \mathrm{~mm}$ and $1300 \mathrm{~mm}$, so the stamping force adjusted accordingly. The equivalent upper die thickness is $130 \mathrm{~mm}$ and feed width is $300 \mathrm{~mm}$. The slider deformation with different mold length and nominal force was shown in Table III. It can be found in Table III that the smaller the mold size, the greater the deformation of the slider under the same stamping force.

\section{TABLE III. SLIDER DEFORMATION WITH DIFFERENT DIFFERENT} MOLD LENGTH AND NOMINAL FORCE/ MM

\begin{tabular}{|c|c|c|c|c|c|}
\hline \multirow{2}{*}{} & \multicolumn{5}{|c|}{ mold length /mm } \\
\cline { 2 - 6 } & 2000 & 1800 & 1600 & 1400 & 1200 \\
\hline $\begin{array}{c}\text { nominal } \\
\text { force/kN }\end{array}$ & 3000 & 3000 & 2000 & 2000 & 1250 \\
\hline $\begin{array}{c}\text { deformati } \\
\text { on/mm }\end{array}$ & 0.19 & 0.22 & 0.16 & 0.19 & 0.13 \\
\hline
\end{tabular}

\section{Partial Load}

For some small size mold the mold was often deviate from the press center. The following settings were made: the die size was $800 \mathrm{~mm}$, the punch force was $800 \mathrm{kN}$, the feed width was $250 \mathrm{~mm}$, and the die rim was $50 \mathrm{~mm}$ away from the center of the slider. Half slider components was taken to analysis (Figure VIII) and the relation between the mold offset and the slider deformation was shown in Table IV. It can be found in Table IV that the slider deformation decreases with the mold installation deviation from the geometric center of the slider 0 $\sim 300 \mathrm{~mm}$ and the deformation increased slightly when the deviation reaching $350 \mathrm{~mm}$. 


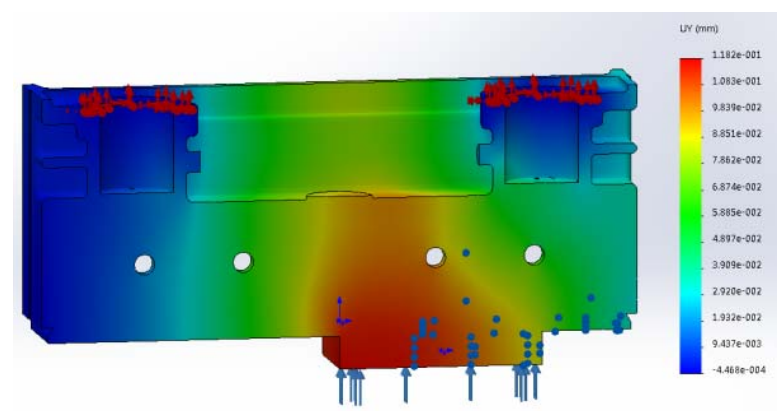

FIGURE VIII. SLIDER PARTS' DISPLACEMENT DIAGRAM(PARTIAL LOAD)

TABLE IV. SLIDER DEFORMATION WITH THE MOLD OFFSET / MM

\begin{tabular}{|c|c|c|c|c|c|c|c|c|}
\hline offset & 0 & 50 & 100 & 150 & 200 & 250 & 300 & 350 \\
\hline $\begin{array}{c}\text { Defor } \\
\text { matio } \\
n\end{array}$ & 0.11 & 0.10 & 0.10 & 0.10 & 0.09 & 0.09 & 0.09 & 0.09 \\
81 & 97 & 60 & 22 & 88 & 53 & 34 & 51 \\
\hline
\end{tabular}

\section{CONCLUSION}

The deformation of the slider will be significantly reduced when the transition plate and the equivalent upper die are taken into account. Under the same pressing force, different feed widths (i.e, the divided area of the equivalent upper die) has little influence on the rigidity of the slider and the thickness of the equivalent upper mold has a greatly affects. When the punch force is same, the smaller the equivalent upper mold's length, the worse the slider rigidity. Biased use helps to reduce the amount of slider deformation when using a small mold.

\section{ACKNOWLEDGEMENTS}

The author wish to thank the Opening Project of Research Department of Intelligent Manufacturing Equipment of Nanjing Institute of Technology (project number: PTKJ201608) and The introduction of talent research fund project of Nanjing Institute of Technology (project number: YKJ201503).

\section{REFERENCES}

[1] Yuzhi Yan. Simulation and Optimization of Operating Mechanism and Frame of the LTH450T High-speed Press[D] (Master Thesis). Jinan: Shandong University, 2014.(in Chinese)

[2] Deyu He. Crank Press[M]. Beijing: China Machine Press, 1981.(in Chinese)

[3] Yunxiao Fan, Congcong Guan, Qisheng Chen and Bo Mou.Optimum Design for Slider of JA39-1200E Press[J]. Coal Mine Machinery, 2012, 33(12):32-34.(in Chinese)

[4] Qisheng Chen. Optimized design of Slider for L4-1200M3 Press[J]. China Metalforming Equipment \& Manufacturing Technology, 2013, 48(5):24-26.(in Chinese)

[5] Junyong Zhan, Jianming Huang and Jinyi Zhang.The Finite Element Analysis and Optimization of Slider in Double-point Press[J]. China Metalforming Equipment \& Manufacturing Technology, 2010, 45(6):4344.(in Chinese)

[6] Huawei Ye and Jianhua Mo. Research on Lightweight Design of Servo Press Slider[J]. Forging \& Stamping Technology, 2016, 41 (2):103-108. (in Chinese)

[7] Chaoxiang Chen and Xiuzi Ye. SolidWorks Simulation Fundamentals (2010 Edition)[M]. Bijing:China Machine Press, 2010.(in Chinese)

[8] Xuanhuai Qun editor. Mechanical Design (Fourth Edition) [M]. Beijing: Higher Education Press, 1997.(in Chinese) 